\title{
The prevalence of vertebral fracture amongst patients presenting with non-vertebral fractures
}

\author{
S. J. Gallacher • A. P. Gallagher • C. McQuillian • \\ P. J. Mitchell • T. Dixon
}

Received: 17 December 2005 / Accepted: 27 July 2006 / Published online: 10 November 2006

(C) International Osteoporosis Foundation and National Osteoporosis Foundation 2006

\begin{abstract}
Introduction Despite vertebral fracture being a significant risk factor for further fracture, vertebral fractures are often unrecognised. A study was therefore conducted to determine the proportion of patients presenting with a nonvertebral fracture who also have an unrecognised vertebral fracture.

Methods Prospective study of patients presenting with a non-vertebral fracture in South Glasgow who underwent DXA evaluation with vertebral morphometry (MXA) from DV5/6 to LV4/5. Vertebral deformities (consistent with fracture) were identified by direct visualisation using the Genant semi-quantitative grading scale.

Results Data were available for 337 patients presenting with low trauma non-vertebral fracture; 261 were female. Of all patients, $10.4 \%$ were aged $50-64$ years, $53.2 \%$ were aged $65-74$ years and $36.2 \%$ were aged 75 years or over. According to WHO definitions, $35.0 \%$ of patients had normal
\end{abstract}

S. J. Gallacher $(\bowtie) \cdot$ A. P. Gallagher · C. McQuillian

Medical Unit, Southern General Hospital,

1345 Govan Road,

Glasgow G51 4TF, UK

e-mail: stephen.gallacher@sgh.scot.nhs.uk

P. J. Mitchell

Merck Sharp \& Dohme Limited,

Hertford Road,

Hoddesdon, Hertfordshire, UK

T. Dixon

JB Medical Ltd,

The Old Brickworks, Chapel Lane, Little Cornard,

Sudbury, Suffolk, UK lumbar spine BMD (T-score -1 or above), $37.4 \%$ were osteopenic (T-score -1.1 to -2.4 ) and $27.6 \%$ osteoporotic (Tscore -2.5 or lower). Humerus $(n=103,31 \%)$, radius-ulna $(n=90,27 \%)$ and hand/foot $(n=53,16 \%)$ were the most common fractures. For $72 \%$ of patients $(n=241)$ the presenting fracture was the first low trauma fracture to come to clinical attention. The overall prevalence of vertebral deformity established by MXA was $25 \%(n=83) ; 45 \%$ $(n=37)$ of patients with vertebral deformity had deformities of more than one vertebra. Of the patients with vertebral deformity and readable scans for grading, $72.5 \%(58 / 80)$ had deformities of grade 2 or 3 . Patients presenting with hip fracture, or spine T-score $\leq-2.5$, or low BMI, or with more than one prior non-vertebral fracture were all significantly more likely to have evidence of a prevalent vertebral deformity $(p<0.05)$. However, $19.8 \%$ of patients with an osteopenic T-score had a vertebral deformity ( $48 \%$ of which were multiple), and $16.1 \%$ of patients with a normal T-score had a vertebral deformity (26.3\% of which were multiple). Following non-vertebral fracture, some guidelines suggest that anti-resorptive therapy should be reserved for patients with DXA-proven osteoporosis. However, patients who have one or more prior vertebral fractures (prevalent at the time of their non-vertebral fracture) would also become candidates for anti-resorptive therapy-which would have not been the case had their vertebral fracture status not been known. Overall in this study, $8.9 \%$ of patients are likely to have had a change in management by virtue of their underlying vertebral deformity status. In other words, 11 patients who present with a non-vertebral fracture would need to undergo vertebral morphometry in order to identify one patient who ought to be managed differently.

Conclusions Our results support the recommendation to perform vertebral morphometry in patients who are 
referred for DXA after experiencing a non-vertebral fracture. Treatment decisions will then better reflect any given patient's future absolute fracture risk. The "Number Needed to Screen" if vertebral morphometry is used in this way would be seven to identify one patient with vertebral deformity, and 14 to identify one patient with two or more vertebral deformities. Although carrying out MXA will increase radiation exposure for the patient, this increased exposure is significantly less than would be obtained if X-rays of the dorso-lumbar spine were obtained.

Keywords Low trauma fracture - Number needed to screen Osteoporosis · Vertebral fracture $\cdot$ Vertebral morphometry

\section{Introduction}

Osteoporosis may be defined as a 'skeletal disorder characterized by compromised bone strength predisposing a person to an increased risk of fracture' [1]. Overall, osteoporotic or low trauma fractures are common - it has been estimated that one in two women and one in five men aged over 50 years will sustain at least one low trauma fracture in their lifetime [2].

The fracture sites which most commonly come to clinical attention include the distal radius (Colles'), proximal femur (hip), humerus and ankle. In the Fracture Liaison Service covering Glasgow, $82 \%$ of presenting fractures were at these sites [3].

The spine is another key fracture site; however, it has been estimated that only $30 \%$ of vertebral fractures receive clinical attention - which means that the majority of patients with vertebral fractures remain undetected [4]. It appears that only those patients with the most severe vertebral fractures come to clinical attention-it is likely that this is due to higher levels of back pain and disability [4].

The European Prospective Osteoporosis Study (EPOS) assessed vertebral fracture incidence in 3,174 men (mean age 63.1 years) and 3,614 women (mean age 62.2 years) over a mean of 3.8 years. The age-standardised incidence of morphometric fracture was $10.7 / 1,000$ person years in women and 5.7/1,000 person years in men [6]. Vertebral fracture incidence increased markedly with age in both men and women. Indeed, the incidence in women aged 50-54 was $3.6 / 1,000$ person years, rising to $29.3 / 1,000$ person years in women aged 75-79 [5].

Lateral dorsal and lumbar X-rays were used in the European Vertebral Osteoporosis Study (EVOS) population to identify vertebral fracture over an 8 -year period. The investigators found an incidence rate of $9.85 / 1,000$ person years compared with $3.06 / 1,000$ person years for hip fracture, 4.28/1,000 person years for Colles' fracture and $4.76 / 1,000$ person years for other fractures [6].

Low trauma fractures have substantial consequences. Although hip fracture has the greatest mortality and morbidity, vertebral fracture is also associated with significant mortality and morbidity. In one study, patients with vertebral deformity had a substantially higher risk of death compared to patients without vertebral deformity, regardless of age, sex and BMD (mortality rate $30.3 \%$ versus $10.7 \%$ over a 14 -year follow-up). The risk of death was highest in those patients with a vertebral deformity who had a subsequent symptomatic fracture [HR 9.0 (3.1-26.0)] [7]. In terms of morbidity, around $70 \%$ of patients with symptomatic vertebral fracture complain of difficulty in standing and $65 \%$ of difficulty in bending, and $41 \%$ complain of constant pain [8].

It is well-established that the presence of one low trauma fracture significantly increases the risk of a further fracture [9-11]. In a systematic review carried out by Klotzbuecher et al. [9], women with a single pre-existing vertebral fracture, identified in eight studies at baseline by vertebral morphometry and in another seven as clinical (symptomatic) fractures, were 4.4-times more likely to have another vertebral fracture than women without vertebral fracture. Prior vertebral fracture also predicted non-vertebral fracture: in women with vertebral fracture, the risk of hip fracture was increased by 2.3-times, of Colles' by 1.4-times and of any non-vertebral fracture by 1.8-times. Fracture risk increased even further with each additional vertebral fracture; for example, the odds of a new vertebral fracture in women with five or more prior vertebral fractures were 35 -times greater than for women without prior vertebral fracture.

Given that vertebral fracture is a significant risk factor for further fracture, and that vertebral fractures often go undiagnosed, this study set out to determine the proportion of patients attending a Fracture Liaison Service following a non-vertebral fracture who also have an unrecognised vertebral fracture.

The standard method to assess vertebral fracture is radiography of the thoraco-lumbar spine [12]. However, there is no gold standard for the definition of osteoporotic vertebral fracture. A number of methods have been developed for interpretation of spinal X-rays, including the Genant semi-quantitative method [13], which has been used as a surrogate 'gold standard' in a number of key osteoporosis studies. This approach is more objective and reproducible than other qualitative methods [12]. Vertebral morphometry using dual-energy X-ray absorptiometry (DXA) also known as morphometric X-ray absorptiometry (MXA) is a fast, low-radiation technique which produces images that are of sufficient quality to be used to diagnose 
the presence of vertebral deformity consistent with fracture [14].

\section{Methods}

The Fracture Liaison Service in South Glasgow has been previously described [3]. This service assumes responsibility for all patients who present with a clinical low trauma fracture and ensures that appropriate assessment, diagnosis and treatment recommendations are made to prevent further fracture. A low trauma fracture is defined as one sustained from a standing height or less, and not occurring as a result of a road traffic accident. Patients with skull or facial fractures are not routinely offered assessment for osteoporosis [3]. All patients aged 50 years or over identified by an Osteoporosis Specialist Nurse have a DXA scan carried out if they are likely to be candidates for bisphosphonate therapy. It should be noted that patients aged over 70 years presenting to this service after hip fracture do not have a DXA scan carried out, since most of these patients have osteoporosis and require therapy.

All patients who presented with a low trauma fracture and who underwent DXA evaluation with vertebral morphometry from DV5/6 to LV4/5 were included in this prospective study. All scans were carried out on a Lunar Prodigy densitometer using the Dual Energy Vertebral Assessment (DVA) morphometry imaging software (version 6.3). Vertebral fractures were identified by direct visualisation using the Genant semi-quantitative grading scale [17]. All scans were reviewed by and vertebral deformities reported by the same physician (SJG). Although Genant's semi-quantitative grading is based on analysis of X-rays and is not validated for MXA, it was used in this study to assess vertebral status on MXA since it provides a practical and pragmatic option.

\section{Statistical analysis}

Baseline differences that potentially explained observed differences in morphometric vertebral fracture rates (sex, age, body mass index, T-score and prior fracture history) were clustered into pre-defined categories:

- Sex: male/female

- Age: 50-64, 65-74, 75+

- $\quad$ Body mass index: $\leq 18 \mathrm{~kg} / \mathrm{m}^{2}, 19-24,25-29, \geq 30 \mathrm{~kg} / \mathrm{m}^{2}$; also compared by quartiles

- T-score: $\geq-1,-2.4$ to $-1.1, \leq-2.5$

- Prior fracture history: yes/no

Contingency tables for each set of categories were prepared and chi-squared values calculated to test for overall interaction. Yates continuity correction was used where $2 \times 2$ tables resulted. Where the overall result was significant, individual pairwise comparisons and $t$-testing were then carried out.

\section{Results}

Data was collected during the routine work of the FLS between September 2004 and March 2005. The data was analysed between July 2005 and July 2006.

\section{Demographics}

Data were available for 337 patients presenting with low trauma fracture; $77.4 \% \quad(n=261)$ were female. Of all patients, $10.4 \%$ were aged 50-64 years, 53.2\% were aged 65-74 years and $36.2 \%$ were aged 75 years or over. Mean body mass index (BMI) was $24 \mathrm{~kg} / \mathrm{m}^{2}$ (SD 32); 6\% ( $\left.n=20\right)$ had a BMI $\leq 18 \mathrm{~kg} / \mathrm{m}^{2}, 33 \%(n=112)$ between $19-24 \mathrm{~kg} / \mathrm{m}^{2}$, $35 \% \quad(n=118)$ between $25-29 \mathrm{~kg} / \mathrm{m}^{2}$ and $26 \% \quad(n=87)$ $\geq 30 \mathrm{~kg} / \mathrm{m}^{2}$ According to WHO definitions, $35.0 \%$ of patients had normal lumbar spine BMD (T-score -1 or above), $37.4 \%$ were osteopenic (T-score -1.1 to -2.4 ) and $27.6 \%$ were osteoporotic (T-score -2.5 or lower).

Humerus $(n=103,31 \%)$, radius-ulna $(n=90,27 \%)$ and hand/foot $(n=53,16 \%)$ were the most common presenting fractures (see Fig. 1). Other fracture sites included hip $(n=16,5 \%)$, clavicle $(n=11,3 \%)$, rib $(n=7,2 \%)$, tibia-fibula $(n=8,2 \%)$, pelvis-pubic rami $(n=7,2 \%)$ and olecranon, patella, scapula, sternum and shaft of femur $(n=7,2 \%)$.

The presenting fracture was the first non-vertebral, low trauma fracture to come to clinical attention in $72 \%$ of patients $(n=241)$, the second in $25 \%(n=85)$, the third in $1 \%$ $(n=5)$ and the fourth in $2 \%(n=6)$.

Information regarding risk factors for fracture-including prior history of fracture, early menopause, BMI, history of smoking or excess alcohol, thyrotoxicosis, history of maternal hip fracture, family history of osteoporosis, steroid use, rheumatoid disease, history of recurrent falls and partial gastrectomy - was also collected. Of all patients, $63 \%$ had one fracture risk factor, $23 \%$ had two risk factors, $11 \%$ had three risk factors and $3 \%$ had more than three risk factors. Risk fractures for fracture were assessed after patients had presented to the FLS with a non-vertebral fracture; therefore, every patient had a prior history of fracture.

Vertebral deformity consistent with fracture

The overall prevalence of vertebral deformity established by MXA was $25 \%$. The prevalence of vertebral deformity by type of presenting fracture is shown in Fig. 1. Patients with a hip fracture were significantly more likely to have a 
Fig. 1 Presenting fracture and prevalence of vertebral deformity for each type of fracture.

* Other includes olecranon, patella, scapula, sternum and shaft of femur

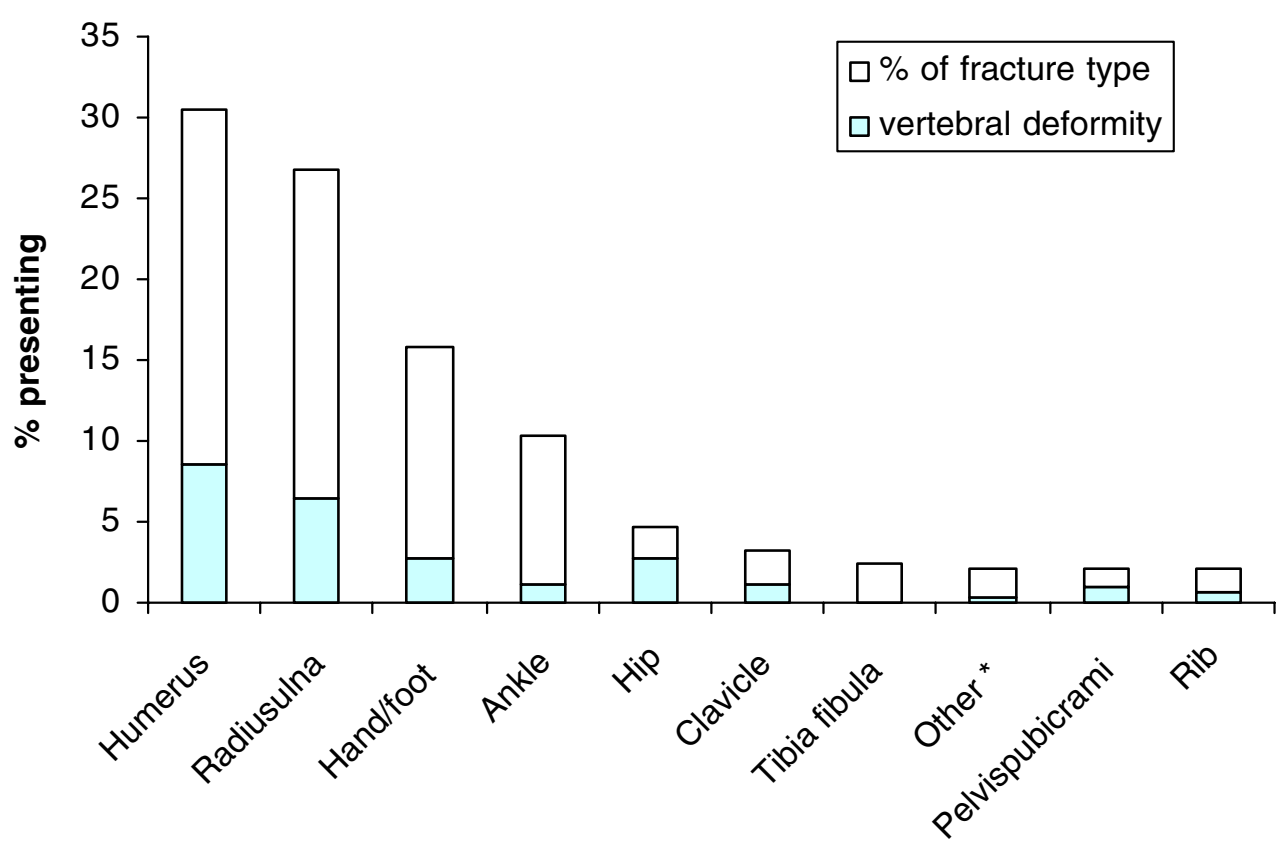

vertebral deformity identified on MXA than were patients who presented with a non-hip fracture $(p=0.009)$.

Overall, $55.4 \%$ of patients with vertebral deformities had deformities in the thoracic spine and $26.4 \%$ had lumbar spine deformities, whilst $18.2 \%$ had deformities in both regions. Of the patients with vertebral deformities identified by MXA, 45\% had deformities of more than one vertebra. Multiple vertebral deformity prevalence varied considerably according to the site of the presenting fracture (see Fig. 2).

Of the patients with vertebral deformities, $3(3.6 \%)$ had unreadable scans for grading. Of the 80 remaining patients, $58(72.5 \%)$ had Grade 2 or Grade 3 deformities. Thirty-two (55.2\%) of the patients with vertebral deformity of Grade 2 and Grade 3 had multiple vertebral fractures. Of the subgroup of patients with vertebral deformity of Grade 2 and 3, $56.9 \%$ had deformities in the thoracic spine, $22.4 \%$ in the lumbar spine and $20.7 \%$ in both regions. There was no significant difference between the vertebral deformity population and the sub-population of patients with Grade 2 or 3 deformities, in terms of the proportion of patients with multiple vertebral deformities or in the site of deformity.

Table 1 shows the prevalence of vertebral deformity and multiple vertebral deformities by lumbar spine T-scores. Patients whose lumbar spine T-scores were consistent within the osteoporosis range (T-score $\leq 2.5$ ) were significantly $(p<0.05)$ more likely to have vertebral deformities $(42 \%)$ than patients whose T-scores were in the osteopenic or normal ranges ( $20 \%$ and $16 \%$ respectively). They were also significantly more likely to have multiple vertebral deformities than those with a normal T-score $(54 \%$ versus $14 \%, p<0.001)$.
Fig. 2 Presenting fracture and prevalence of multiple (two or more) vertebral deformities

\section{$\%$ multiple vertebral deformities}

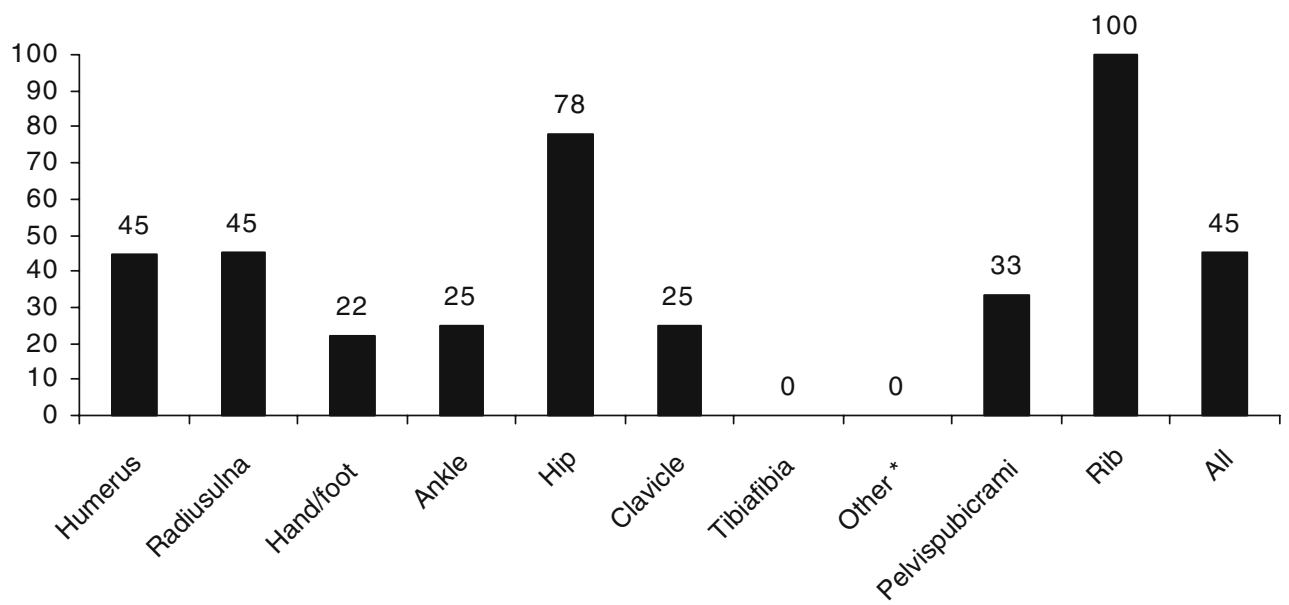


Table 1 Impact of lumbar spine T-score on prevalence of vertebral deformity

\begin{tabular}{|c|c|c|c|c|c|c|c|c|c|c|c|}
\hline \multirow[t]{2}{*}{ Lumbar spine T-score } & \multicolumn{2}{|c|}{ Total } & \multicolumn{3}{|c|}{ Vertebral deformity } & \multicolumn{3}{|c|}{ Multiple vertebral deformities } & \multicolumn{3}{|c|}{ Fracture Grade 2 or 3} \\
\hline & $n$ & $\%$ & $n$ & $\%$ & $\%^{\mathrm{a}}$ & $n$ & $\%$ & $\%$ & $n$ & $\%$ & $\%{ }^{\mathrm{a}}$ \\
\hline Osteoporotic (T-score $\leq-2.5$ ). & 93 & 28 & 39 & 47.0 & 41.9 & 20 & 54 & 51.3 & 32 & 55.2 & 34.4 \\
\hline Osteopenic (T-score $-2.4--1.1$ ). & 126 & 37 & 25 & 30.1 & 19.8 & 12 & 32 & 48.0 & 16 & 27.6 & 12.7 \\
\hline Normal & 118 & 35 & 19 & 22.9 & 16.1 & 5 & 14 & 26.3 & 10 & 17.2 & 8.5 \\
\hline Totals & 337 & 100 & 83 & 100 & & 37 & 100 & & 58 & 100 & \\
\hline
\end{tabular}

Vertebral deformity: Chi-squared $=13.471, p=0.0012$

Multiple vertebral deformities: Chi-squared $=16.304, p=0.0003$

a $\%$ within each T-score group with vertebral deformity

$\mathrm{b}_{\%} \%$ of vertebral deformity group with multiple deformities within each T-score group

Patients with lower BMI $\left(\leq 18 \mathrm{~kg} / \mathrm{m}^{2}\right)$ were significantly more likely to have vertebral deformity than patients with the highest BMI $\left(\geq 30 \mathrm{~kg} / \mathrm{m}^{2}\right),(40 \%$ versus $17 \%, p<0.0001)$ (Table 2). A very similar picture was seen when BMI was divided into quartiles: $45 \%$ of patients in the lowest quartile had a vertebral deformity, compared with $18 \%$ of those in the highest quartile $(p<0.0001)$. The mean BMI for patients with and without vertebral deformity did not differ significantly $\left(24.35 \pm 4.78 \mathrm{~kg} / \mathrm{m}^{2}\right.$ vs $\left.25.22 \pm 3.90 \mathrm{~kg} / \mathrm{m}^{2}\right)$, nor did the mean BMI of patients with multiple vertebral deformities $\left(23.70 \pm 4.78 \mathrm{~kg} / \mathrm{m}^{2}\right)$.

Patients with a history of one or more non-vertebral fractures prior to the fracture they presented with were significantly more likely to also have vertebral deformity (ies) (Table 3), (43\% versus 20\%, $p=0.008)$.

Table 1 also includes analysis of the sub-group of patients with vertebral deformities of Grade 2 and Grade 3

- Patients with an osteoporotic T-score were significantly more likely to have vertebral deformities than those with a normal or osteopenic T-score $(34 \%$ vs $12.7 \%$ [osteopenic] and $8.5 \%$ [normal] $p<0.0001$ )

- Patients with BMI $<18 \mathrm{~kg} / \mathrm{m}^{2}$ were significantly more likely to have vertebral deformities than those with BMI of over $\geq 30 \mathrm{~kg} / \mathrm{m}^{2}$ ( $40 \%$ vs $\left.10.3 \%, p<0.0001\right)$

- Patients with a history of one or more prior nonvertebral fractures were more likely to have vertebral deformity although this did not reach significance $(24 \%$ vs $15 \%, p=0.055$ )

Older patients were slightly (although not statistically significantly) more likely to have a vertebral deformity: $30 \%$ of patients aged over 75 had a vertebral deformity, compared with $23 \%$ and $22 \%$ of patients aged $50-64$ years and 65-74 years respectively. Gender did not appear to affect the likelihood of identifying a vertebral deformity ( $25 \%$ of women and $24 \%$ of men), although women were somewhat more likely to have multiple vertebral deformities $(45 \%$ vs $40 \%, p=\mathrm{ns})$.

\section{Discussion}

One-quarter of patients presenting to our Fracture Liaison Service with a non-vertebral fracture had a previously undiagnosed vertebral deformity, of which almost one-half $(45 \%)$ were multiple vertebral deformities. This is similar to the prevalence seen in previous studies using radiographic or MXA detection in women with and without nonvertebral fracture. Sub-analysis of patients by grade of deformity revealed that almost three-quarters of the patients had vertebral deformities of Grade 2 and Grade 3. These are more likely to be vertebral fractures, rather than vertebral deformities of non-osteoporosis aetiology, which might be more likely where Grade 1 deformities are present.

Table 2 Impact of BMI on prevalence of vertebral deformity, $n=336$

\begin{tabular}{|c|c|c|c|c|c|c|c|c|c|c|c|}
\hline \multirow[t]{2}{*}{ BMI } & \multicolumn{2}{|c|}{ Total } & \multicolumn{3}{|c|}{ Vertebral deformity } & \multicolumn{3}{|c|}{ Multiple vertebral deformities } & \multicolumn{3}{|c|}{ Fracture Grade 2 or 3} \\
\hline & $n$ & $\%$ & $n$ & $\%$ & $\%$ & $n$ & $\%$ & $\%$ & $n$ & $\%$ & $\%$ \\
\hline Underweight $<18$ & 20 & 6.0 & 8 & 9.6 & 40.0 & 5 & 13.5 & 62.5 & 8 & 13.8 & 40.0 \\
\hline Normal 19-24 & 111 & 33.0 & 39 & 47.0 & 35.1 & 20 & 54.1 & 51.3 & 24 & 41.4 & 21.6 \\
\hline $25-29$ & 118 & 35.1 & 22 & 26.5 & 18.6 & 6 & 16.2 & 27.3 & 17 & 29.3 & 14.4 \\
\hline $30+$ & 87 & 25.9 & 14 & 16.9 & 16.1 & 6 & 16.2 & 42.9 & 9 & 15.5 & 10.3 \\
\hline Totals & 336 & 100 & 83 & 100 & & 37 & 100 & & 58 & 100 & \\
\hline
\end{tabular}

Vertebral deformity: Chi-squared $=16.572, p=0.0009$

Multiple vertebral deformities: Chi-squared $=15.288, p=0.0016$ 
Table 3 Impact of prior fracture history on prevalence of vertebral deformity

\begin{tabular}{|c|c|c|c|c|c|c|c|c|c|c|c|}
\hline & \multicolumn{2}{|c|}{ Total } & \multicolumn{3}{|c|}{ Vertebral deformity } & \multicolumn{3}{|c|}{ Multiple vertebral deformities } & \multicolumn{3}{|c|}{ Fracture Grade 2 or 3} \\
\hline & $n$ & $\%$ & $n$ & $\%$ & $\%$ & $n$ & $\%$ & $\%$ & $n$ & $\%$ & $\%$ \\
\hline 0 & 241 & 71.5 & 49 & 59.0 & 20.3 & 24 & 64.9 & 49.0 & 35 & 60.3 & 14.5 \\
\hline 1 or more & 96 & 28.5 & 34 & 41.0 & 42.7 & 13 & 35.1 & 38.2 & 23 & 39.7 & 24.0 \\
\hline Totals & 337 & 100 & 83 & 100 & & 37 & 100 & & 58 & 100 & \\
\hline
\end{tabular}

Vertebral deformity: Chi-squared $=7.131, p=0.0078$

Multiple vertebral deformities: Chi-squared $=0.237, p=0.63$ (ns)

In the Study of Osteoporotic Fractures (SOF), a prospective study of almost 10,000 women, the prevalence of vertebral fracture was $20 \%$ (42\% of which were multiple) in women aged over 65 years who did not have a non-vertebral fracture [11]. In another study of 482 women aged over 65 years without a non-vertebral fracture, the prevalence of vertebral fracture was $18.3 \%$ [15]. In a smaller study of 58 women with Colles' fracture, vertebral fractures were identified by MXA in 19\% of patients [16].

In this present study, patients presenting with hip fracture, spine T-score $\leq-2.5$, low BMI (either in the lowest quartile or $\leq 18 \mathrm{~kg} / \mathrm{m}^{2}$ ) or with more than one prior non-vertebral fracture were all significantly more likely to have evidence of a prevalent vertebral deformity. However, we found that $16 \%$ of patients with normal BMD at the lumbar spine had a prevalent vertebral deformity $(26 \%$ of which were multiple). This is comparable to that seen in an earlier study conducted in women aged over 65 years without a non-vertebral fracture and with normal BMD at the spine, which revealed a prevalence of vertebral fracture of $18.7 \%$ [15].

In the UK, current treatment decisions for patients with low trauma fracture are based on fracture status and BMD as determined by DXA [17, 18]. In England, patients aged under 75 receive treatment if they have a fracture and osteoporosis is confirmed by DXA scanning [17]. In Scotland, patients with vertebral fracture and BMD outside the osteoporotic range, as defined by the WHO classification, do not routinely receive treatment unless they have two or more vertebral fractures, irrespective of BMD, or one vertebral fracture and an osteopenic BMD score [18]. Identification of those patients who already have an (often unrecognised) prior vertebral fracture is particularly important, as they are at high risk of further fracture by virtue of their prior vertebral fracture. Although these patients might not fulfil the criteria for therapy on the basis of their (nonvertebral) fracture history and BMD, they might be candidates for therapy if their underlying positive vertebral fracture status was known.

In this study, five of the 118 patients with normal BMD (4.2\%) had two or more previously undiagnosed vertebral deformities plus a new non-vertebral fracture, and 25 of the
126 patients with osteopenic BMD (19.8\%) had one or more previously undiagnosed vertebral deformities plus a non-vertebral fracture. These patients would not have been candidates for anti-resorptive treatment if MXA had not been performed and their vertebral deformities identified. Therefore, one in 20 patients with a normal T-score and almost one in five patients with an osteopenic T-score would experience a change in management by virtue of their underlying vertebral deformity or deformities.

Overall, $30(8.9 \%)$ of the patients in this study would be eligible for treatment by virtue of their newly identified vertebral deformity., which means that 11 patients who present with a non-vertebral fracture would need to undergo vertebral morphometry in order to identify one patient who ought to be managed differently. This 'Number Needed to Screen' gives an indication of the number of patients for whom treatment recommendations would change after the identification of vertebral fracture.

These data also provide the first attempt to quantify the overlap between patient populations with non-vertebral and vertebral fracture. Estimates suggest that 1.28 million postmenopausal women in the UK have experienced a prior non-vertebral fracture [19] and 1.3 million have at least one prior vertebral fracture [20]. In this study, $72 \%$ of patients presented with their first non-vertebral fracture, and vertebral morphometry subsequently identified vertebral deformities in one in five $(21 \%)$ of these patients. Nearly one-half of vertebral deformities were multiple (48\%). It is highly likely that these vertebral fractures had occurred prior to the first non-vertebral fracture, suggesting that a substantial number of patients will have experienced a vertebral fracture prior to any non-vertebral fracture event.

Our results support the recommendation to perform vertebral morphometry in any patient who is referred for DXA testing after experiencing a non-vertebral fracture. Treatment decisions will then better reflect any given patient's future absolute fracture risk. The 'Number Needed to Screen' if MXA is used in this way would be seven to identify one patient with vertebral deformity, and 14 to identify one patient with two or more vertebral deformities.

Routinely performing lateral vertebral morphometry does raise a number of issues. Firstly, there is an increase 
in radiation exposure for the patient. A standard AP spine and hip DXA scan is associated with a radiation exposure [entrance surface dose (ESD)] of around $0.037 \mathrm{mGy}$, and results in an effective dose of less than $2 \mu \mathrm{Sv}$ (microsieverts). The ESD associated with lateral vertebral morphometry is $0.083 \mathrm{mGy}$ [21],corresponding to an estimated effective dose of about $2.5 \mu \mathrm{Sv}$. These are relatively small doses compared to the UK natural background radiation level of approximately $2.5 \mathrm{mSv}$. The small carcinogenic potential associated with these scans has to be balanced against both the prognostic importance (in terms of future fracture risk) that is associated with the identification of unrecognised vertebral deformities and also the much higher radiation exposure risk associated with plain spine radiology (effective dose $\sim 0.6 \mathrm{mSv}$ ).

Lateral vertebral morphometry does have limitations; for example, it is less reliable than conventional lateral spine $\mathrm{X}$-rays at the upper thoracic spine and in Grade 1 deformities.

A recent study [22] comparing MXA with lateral spine $\mathrm{X}$-rays found that vertebral morphometry using MXA allowed diagnosis of vertebral fracture in the lumbar and mid thoracic spine, where vertebral fractures are most common. MXA was less reliable at the upper thoracic spine, which is also an established limitation of X-rays.

An earlier study [23] compared identification of vertebral fracture on MXA using the Genant semi-quantitative method using MXA with conventional X-rays in 80 postmenopausal women. Of the 1,027 potentially evaluable vertebrae, $81 \%$ were adequately visualised on MXA to allow grading. Prevalent vertebral fracture was identified in 40 vertebral bodies using X-ray; of these, 28 (70\%) were correctly identified on MXA, 17/18 (95\%) Grade 2 or 3 and $11 / 22(50 \%)$ of Grade 1 fractures. Of the non-fractured vertebrae, $96.2 \%$ were correctly classified as normal by MXA.

Although the Genant semi-quantative method is not validated for MXA, it has been used in other studies [22, 23], and was used in this study as a pragmatic option. To carry out quantitative analysis on each scan would have been time-consuming and impractical.

Given that the sample population had already had at least one non-vertebral fracture $(28 \%$ had more than one prior fracture), were drawn from the FLS population, and that almost three-quarters had Grade 2 or 3 vertebral deformity, it seems reasonable to expect the vertebral deformity to be due to osteoporosis, rather than other diagnoses such as degenerative change or Scheurmann's disease.

The sensitivity of detection of a vertebral fracture is lower both where there is significant spine scoliosis and also where there is marked disc-space osteoarthritic change. In these settings, proceeding to plain spine radiology would be recommended [24]. Plain spine X-rays were not carried out in this study. Furthermore, in keeping with our local protocol, bone densitometry was not carried out in older patients (over the age of 70) after hip fracture. Both of these features may mean that the overall prevalence of vertebral deformity in this population has been underestimated.

In conclusion, undiagnosed vertebral deformity is highly prevalent in patients aged over 50 years who present with a new non-vertebral fracture. Given that prior vertebral fracture significantly increases the risk of further fracture and because newer diagnostic techniques make identification of vertebral deformity consistent with fracture relatively straightforward with minimal radiation exposure, we recommend that all patients undergoing DXA should also undergo vertebral morphometry to identify prior vertebral deformities consistent with fractures.

Acknowledgements This work was supported by an unrestricted educational grant from Merck Sharp \& Dohme Limited. The views expressed in this publication are those of the authors, and not necessarily those of the publisher or sponsor.

We would like to acknowledge the advice and assistance of Dr Lois Wehren, University of Maryland, in the preparation of this manuscript.

\section{References}

1. Osteoporosis prevention, diagnosis and therapy (2000) NIH Consensus Statement 17(1):1-36

2. van Staa TP, Dennison EM, Leufkens HG et al (2001) Epidemiology of fractures in England and Wales. Bone 29:517-522

3. McLellan AR, Gallacher SJ, Fraser M, McQuillian C (2003) The fracture liaison service: success of a program for the evaluation and management of patients with osteoporotic fracture. Osteoporos Int 14:1028-1034

4. Cooper C, O'Neill T, Silman A; on behalf of the European Vertebral Osteoporosis Study Group (1993) The epidemiology of vertebral fractures. Bone 14:S89-S97

5. The European Prospective Osteoporosis Study (EPOS) group (2002) Incidence of vertebral fracture in Europe: results from the European Prospective Osteoporosis Study (EPOS). J Bone Miner Res 17:716-724

6. Naves M, Diaz-López JB, Gómez C et al (2003) The effect of vertebral fracture as a risk factor for osteoporotic fracture and mortality in a Spanish population. Osteoporos Int 14:520-524

7. Pongchaiyakul C, Nguyen ND, Jones G et al (2005) Asymptomatic vertebral deformity as a major risk factor for subsequent fractures and mortality: a long-term prospective study. J Bone Min Res 8:1349-1355

8. Scane AC, Sutcliffe AM, Francis RM (1994) The sequelae of vertebral crush fractures in men. Osteoporos Int 4:89-92

9. Klotzbuecher CM, Ross PD, Landsman PB et al (2000) Patients with prior fractures have an increased risk of future fractures: a summary of the literature and statistical synthesis. J Bone Miner Res 15:721-739

10. Kanis JA, Johnell O, De Laet C et al (2004) A meta-analysis of previous fracture and subsequent fracture risk. Bone 35:375-382

11. Black DM, Arden NK, Palermo L, Pearson J et al (1999) Prevalent vertebral deformities predict hip fractures and new vertebral deformities but not wrist fractures. Study of Osteoporotic Fractures Research Group. J Bone Miner Res 14:821-828 
12. Ferrar L, Jiang G, Adams J et al (2005) Identification of vertebral fractures: an update. Osteoporos Int 16:717-728

13. Genant HK, Wu CY, van Kuijk C et al (1993) Vertebral fracture assessment using a semiquantitative technique. J Bone Miner Res 8:1137-1148

14. Rea JA, Li J, Blake GM, Steiger P et al (2000) Visual assessment of vertebral deformity by X-ray absorptiometry: a highly predictive method to exclude vertebral deformity. Osteoporosis Int 11:660-668

15. Greenspan SL, von Stetten E, Emond SK (2001) Instant vertebral assessment. J Clin Densitom 4:373-380

16. Kanterewicz E, Yañez A, Del Rio L et al (2003) Vertebral morphometric x-ray absorptiometry in women with Colles' fracture. J Clin Densitom 6:359-365

17. National Institute for Clinical Excellence (2005) Bisphosphonates (alendronate, etidronate, risedronate), selective oestrogen receptor modulators (raloxifene) and parathyroid hormone (teriparatide) for the secondary prevention of osteoporotic fragility fractures in postmenopausal women. Technology Appraisal 87. January 2005

18. Scottish Intercollegiate Guidelines Network (2003) Management of osteoporosis. SIGN 71. June 2003
19. Robinson CM, Royds M, Abraham A, McQueen MM, CourtBrown CM, Christie J (2002) Refracture in patients at least 45 years old. A retrospective analysis of twenty-two thousand and sixty patients. J Bone Joint Surg Am 84:1528-1533

20. O’Neill TW, Felsenberg D, Varlow J, Cooper C, Kanis JA, Silman AJ (1996) The prevalence of vertebral deformity in European man and women: the European Vertebral Osteoporosis Study. J Bone Miner Res 11:1010-1018

21. Lunar Prodigy, Prodigy Advance, DPX-Pro/NT/MD+/Duo/Bravo. Safety Information and Technical Specifications. enCORE safety and specification manual. Rev C 10/2003 L10855. http://www. gemedicalsystems.com

22. Chapurlat RD, Deboeuf F, Marion-Audibert HO et al (2006) Effectiveness of instant vertebral assessment to detect prevalent vertebral fracture. Osteoporos Int 17:1189-1195

23. Binkley N, Krueger D, Gangon R et al (2005) Lateral vertebral assessment: a valuable technique to detect clinically significant vertebral fractures. Osteoporos Int 16:1513-1518

24. Schousboe JT, DeBold CR (2006) Reliability and accuracy of vertebral fracture assessment with densitometry compared to radiography in clinical practice. Osteoporos Int 17:281-289 